\title{
The Release of Desire: Three Levels of Spatial Expression of Beam in Modern and Contemporary Reinforced Concrete Architecture
}

\author{
Liu, Yang a \\ aRWTH Aachen University. yang.liu5@rwth-aachen.de
}

https://doi.org/10.4995/CIAB9.2020.10599

\begin{abstract}
In contemporary context the discipline gap between Structural Engineering and Architecture to some extent leads to the loss of the spatial expression desire of structural members. Two conditions are presented in a large number of common contemporary building projects: Rough - lacking the architectural perspective control over the scale and layout of structural members, Absence - hiding the beams with decorative elements such as suspended ceiling. Actually, as one of the most important structural members in a building, the beam has great potential for spatial expression. Since the beam plays an increasingly more important role, three progressive levels could be characterized: spatial scenery - as the fifth elevation, spatial prop - participating in the generation of form, spatial protagonist - leading the order of spatial tectonic. According to the above three levels, classification and analysis to several modern and contemporary buildings, especially several reinforced concrete buildings of the 1960s and 1970s, may be helpful in exploring the methodology against these two above trends of contemporary construction Industry.
\end{abstract}

Key Words: beam, reinforced concrete, spatial expression, structural member

\section{Introduction}

Since time immemorial human construction activities cannot avoid spatial concepts of beam structures. Since the nineteenth century the invention of reinforced concrete material is accompanied by advances in structural engineering science, and it is possible to enrich the forms of beam. However, the natural pursuit of pure space concepts under the influence of abstract art, with the discipline gap of structural engineering and architecture, makes structural members to some extent just a tool to serve the realization of abstract space. So the character of the beam in the modern and contemporary context is somehow embarrassing: beneath the floor slab, the beam may become a negative factor in the concept pure space; located above the horizontal line of sight and physical activity of the people, the beam easily becomes a structural member that is ignored by users and even architects; modern building environment relies on mechanical equipment, and the beam often becomes an obstacle in placing pipes. Either the visual existence of beam is canceled, such as Le Corbusier's DomIno system; or the beam itself is completely ignored without any architectural operation or roughly covered by suspended ceilings together with mechanical pipelines. As a result, the beam lost the possibility of spatial expression in large numbers of modern and contemporary buildings. 


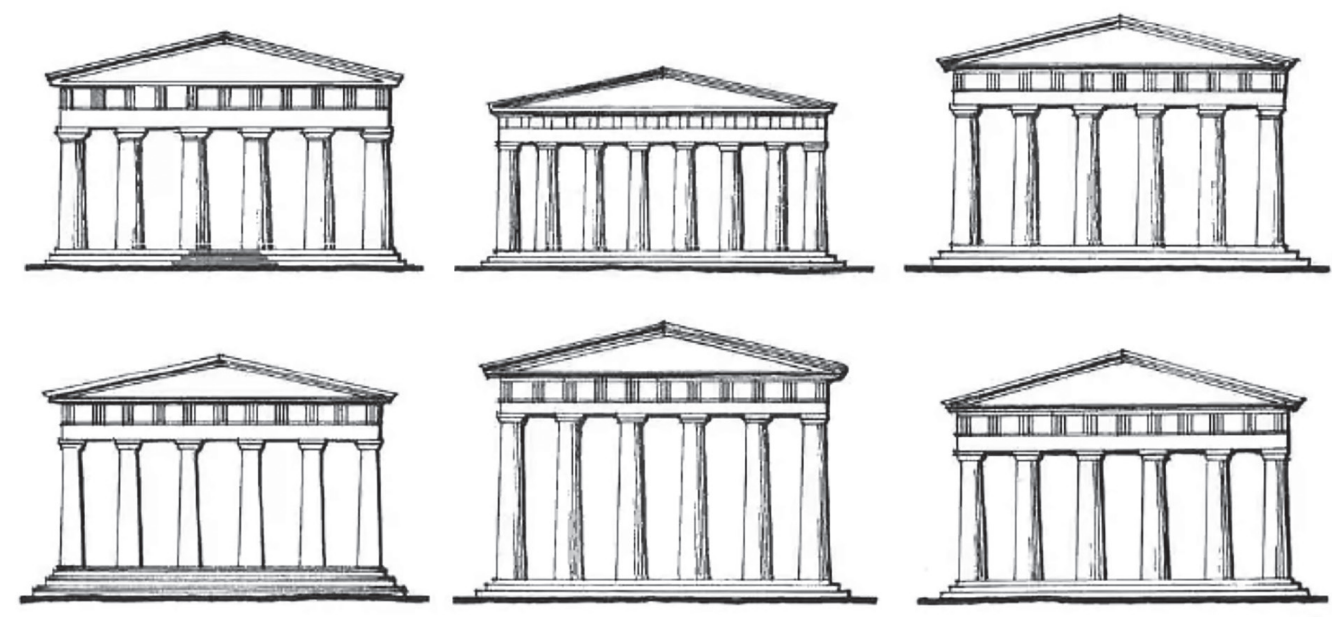

Figure 1. The Pediment of the Greek Temples. Pier Luigi Nervi. 1965. Pier Luigi Nervi, Aesthetics and Technology in Building, trans. Robert Einaudi (Cambridge: Harvard University Press, 1965), 11.

\section{Spatial Concept of Beam Structure in Ancient Construction}

Humans have had the concept of beam structures from ancient times. The Stonehenge in the Neolithic Age might be seen as one of the earliest beam structures built by mankind. A 7-ton stone strip was attached to two columns to form a simply supported beam and then arranged to a concentric circle. Goemetric meanings remains a mystery, the simple form and arrangement of the beams show a strong geometric composition and a desire to resist the gravity. In the book Aesthetics and Technology in Building Pier Luigi Nervi once questioned the meaning that the span of the beams at the two ends equal to the middle beams in the pediments of the Greek temples ${ }^{1}$ (fig. 1). If the usual understanding of letting the corner columns adduct and enhance its feeling of stable is not the constructor's starting point, then the consistency of beams span and the difference of columns distance may stem from the pursuit of space under such a technical constraint: let each stone beam reach the maximum span under uniform cross-section conditions. After all, the material properties are such that the horizontal span is especially valuable when the stone is utilized as a horizontal loadbearing member. The spanning capability of these stone beams determines the adducting of two corner columns and then involves the monolith of the whole temple. In the East there are also a few allusions to the relationship between the beam and the space. In Chinese "the reverberation around the beams, incessant more than three days" is used to describe the endless aftertaste of a music. ${ }^{2}$ Why is the reverberation around the beams rather than the columns or other elements? Physically, the stacked structure of the beams beneath the roof provides space for multiple reflections of sound waves. Although the surrounding music is invisible, by imagination, the picture is vividly presented in our minds. Besides, another Chinese allusion literally translated "Gentleman on the Beam" is used to refer to the thief. ${ }^{3}$ In the East Asian wooden houses, the beams are usually above people's sight of daily living, which can provide space for thieves to hide. Yoshijima Heritage House and Kusakabe Folk Museum in Takayama, Japan (fig. 2), reflects this kind of spatiality of the beam vividly.

\section{Form Dilemmas and Incisive Views of Reinforced Concrete Pioneers}

Unlike masonry and timber, the plasticity of reinforced concrete made the pioneers of modern times face the problem of how to express it in a proper way. In 1897, French engineer François Hennebique solved the problem of shearing of reinforced concrete beams with stirrups and obtained patents (fig. 3). The synthesis of 

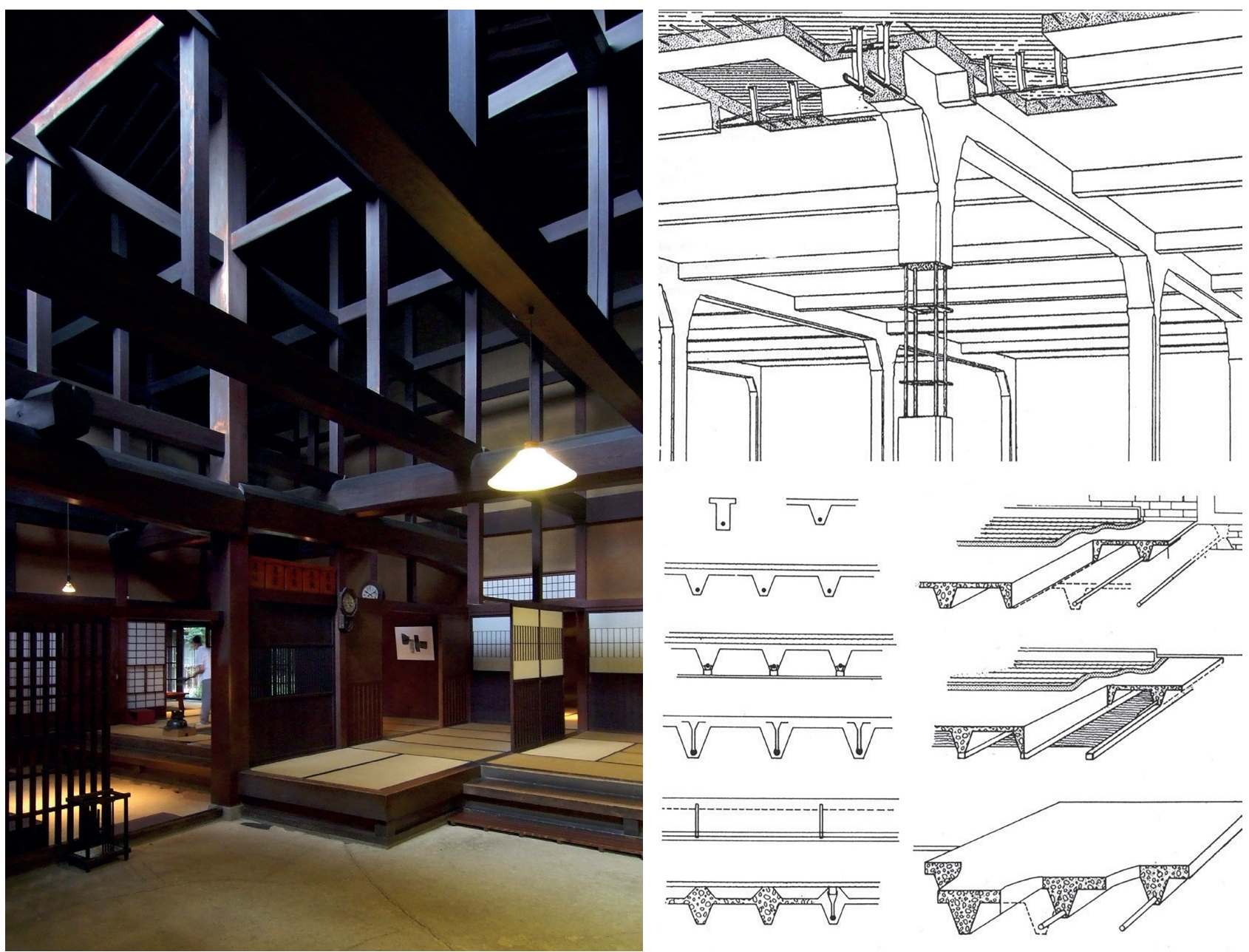

Figure 2. Yoshijima Heritage House in Takayama, Japan, 1907. Wikimedia user Wiiii. 2008.

Figure 3. Hennebique Reinforced Concrete System. François Hennebique. 1897. Kenneth Frampton, Studies in Tectonic Culture: The Poetics of Construction in Nineteenth and Twentieth Century Architecture (Cambridge: MIT Press Ltd., 1995), 126.

different elements of the structure like beams and pillars forms a monolithic frame structure. Despite adopting François Hennebique's technology, ${ }^{4}$ Auguste Perret tried to morph beam and column in a uniform section size in the joint, rather than the typical haunched beam in François Hennebique frame system. Auguste Perret intended to express the framework itself as the basic structure of a building, with particular emphasis on the difference between the structural frame and the enclosure wall through the beam-column transfer relationship of the joint (fig. 4). Mies van der Rohe also pointed out that "Reinforced concrete structures are skeletons by nature." In his Reinforced Concrete Office Building Project, 19221923 (fig. 5), Mies explained "Functional division of the workspace determines the width of the building: 16 meters. The most economic system was found to be two rows of columns spanning 8 meters with 4 meters cantilevered on either side. The girders are spaced 5 meters apart. These girders carry the floor slabs, which at the end of the cantilevers are turned up perpendicularly to form the outer skin of the building." Nevertheless, the profound insights of these pioneers did not receive sufficient consideration in the subsequent architectural practices. Coupled with the impact of post-modernism, the trend of exploration in related directions vanished rapidly, leaving only a certain number of fragmentary cases around the world. 


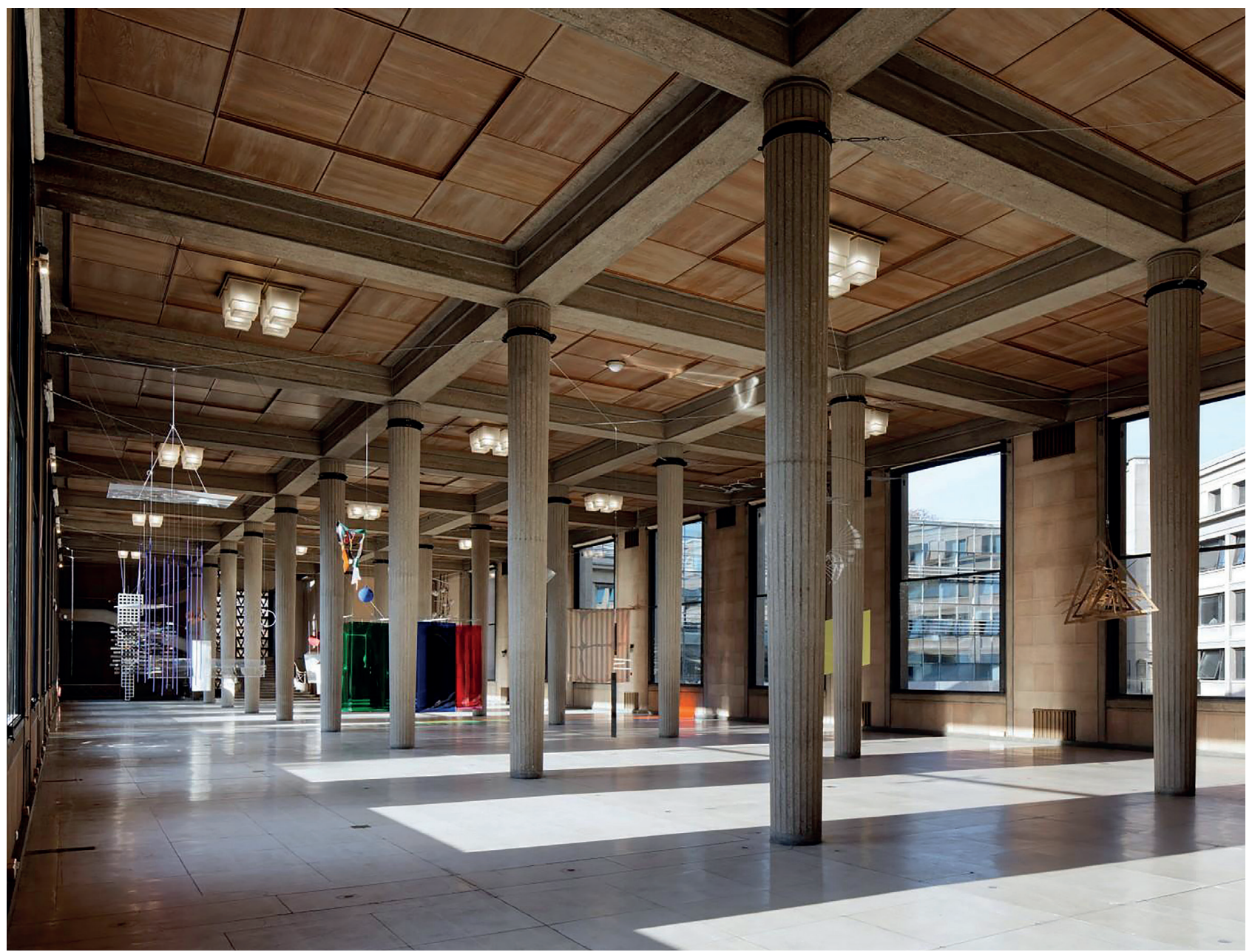

Figure 4. Palais d'léna, Auguste Perret, 1934. Benoît Fougeirol. 2018. Palais d’lena, Paris, France. Courtesy Olivier Malingue Ltd.

\section{Spatial Scenery - As the Fifth Elevation}

Cubic volume is a kind of space operation prototype that modern architects are obsessed with. As a linear element in a building volume, besides the load-bearing function, the beams that under the control of structural logic and geometric order always has a great impact on the visual effect of the top surface, and become a representative fifth facade of a building.

\section{(a) Point: Size and Shape.}

A point in the geometric sense has specific location but not size, its existence is just for defining spatial coordinates. A point in the structural engineering sense usually emphasis the joint, which is the connecting part between two structural members. Nevertheless, from the perspective of architectural form, the point is neither a pure spatial coordinate in geometric, nor a specific joint in structural engineering. In terms of plane composition, point is a kind of visual unit with spatial position, which has a relative size and shape. How much area can be considered as a point? What shape can be treated as a point? The actual size and shape of a building component has little effect on the human visual judgment. The key factor is its relative size and figure-ground relation with the surrounding constituent elements. 


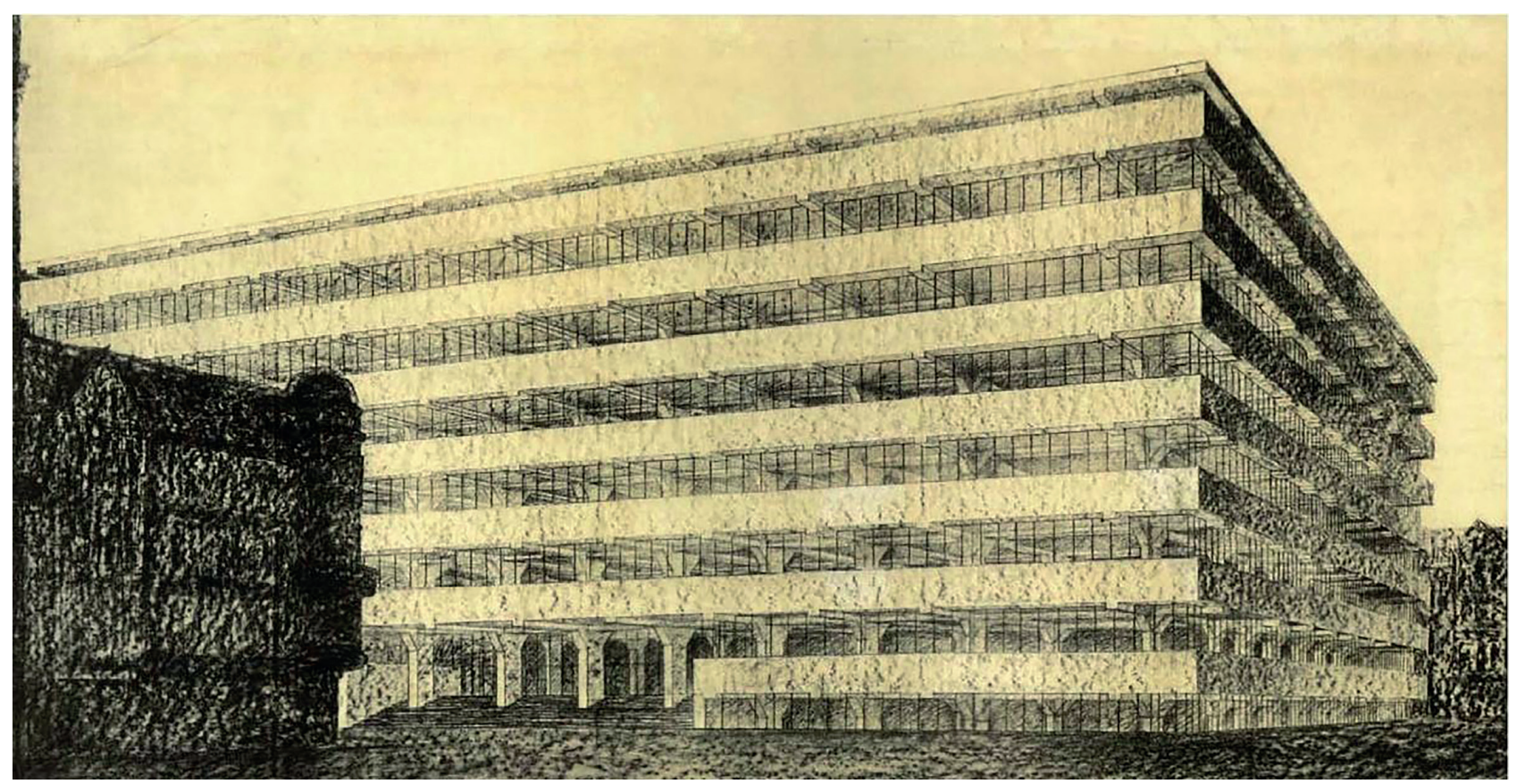

Figure 5. Reinforced Concrete Office Building Project, Mies van der Rohe, 1922-1923. 2019. MoMA. Artists Rights Society (ARS), New York / VG Bild-Kunst, Bonn.

The spatial expression of a beam as a point constituting element is always achieved by its section. Different from the image of standingupright in vertical space that most churches present, the form of Church of Mater Misericordiae at Baranzate, Milan, 1956 (fig. 6) is a simple and restrained glass box. On the top of the main elevation of the box, six girders with respectively prestressed by 30 precast concrete members are abruptly cut off with $300 \mathrm{~mm}$ outstretch end from the glass envelope. The expressive $X$ sections of the concrete beams are exposed on the elevation. On the $15 \mathrm{~m} \times 9 \mathrm{~m} \times 29 \mathrm{~m}$ background of the glass box, the $X$ section of $600 \mathrm{~mm}$ wide and $1000 \mathrm{~mm}$ height shrink to a visual point. At night the interior parts of the beams are faintly visible through the glass. The composition rule of point extending to line, the clear structural expression of the prefabricated members, and the inner force of the post-tensioning prestressed steel strands could be perceived intensively.

\section{(b) Line: Thickness and Density.}

The trace of a point movement forms a line. The geometrical line has length but not thickness degree, and its existence is just for measuring the extending length. On the contrary, the line in the sense of the plane composition has thickness degree, and between two lines the degree of density can be defined. Lines can not only be connected to other constituent elements, but also define and divide a spatial volume. From the abstract analysis of plane composition back to the concrete view of the architectural entity: linear elements can be connected to different structural members, can outline the shape of the building, can enrich the texture of the facade. Lines can be connected to and support other constituent elements, and can also define and divide the spatial extent. From the abstract analysis of the relationship, back to the concrete view of the architectural entity: the linear elements can be connected to different structural members, which can also outline the shape of a building and enrich the texture of a facade. Specifically, the primary beams and the secondary beams in a building usually have different sizes thought they are all liner elements, while the different sizes reflect their order of forces. Even between the beams of the same level, the visual density degree depends not only on the axis, but also on the thickness of the beam itself.

In the Caja Granada Savings Bank (fig. 7) the ceiling constructed by four primary beams with a width of $3 \mathrm{~m}$ and several secondary beams with a width of $300 \mathrm{~mm}$ covers the Atrium. The huge difference between the sizes of the primary beams and the secondary beams contribute to Alberto Campo Baeza's expression on "Idea, Light and Gravity." 


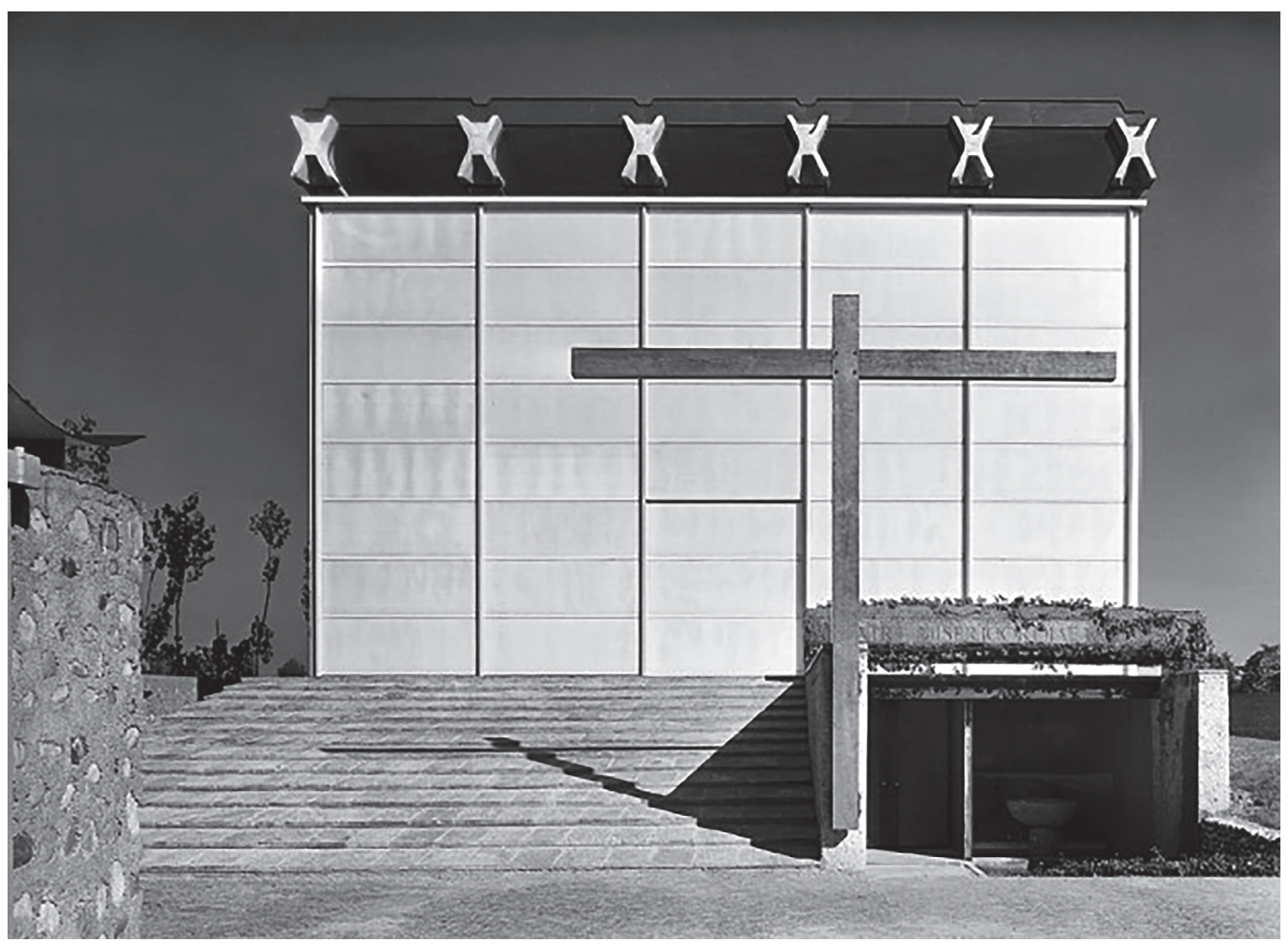

Figure 6. Church of Mater Misericordiae at Baranzate, Milan, Angelo Mangiarotti, Bruno Morassutti and Aldo Favini 1956. Anonymous. 2004. Fondazione Aldo Favini.

\section{(c) Plane: Depth and Weight.}

The trace of a line movement forms a plane. The geometrical plane has area but not depth degree, and its existence is just for measuring the extending area. In terms of structural and architectural form, the most typical surface-shaped member is the slab, which can be distinguish by deep or shallow, heavy or light. In a building the contradiction between the strength and the weight of the slab makes the beams act as a protagonist of horizontal load-bearing and spatial expression. When the parallel ribs of a rib-beam slab and the crossing beams of a waffle slab intense to a certain extent, several lines weave a plane, and several ribs approach a slab. Compared with the smooth surface of thick reinforced concrete slab, the plane formed by rib beams and the waffle beams has much greater potential of spatial expression: the height and density of beams are constrained by not only the contradiction of structural strength and interior height, but also the balance of project costs and formwork erecting difficulty. In the game of many factors, this special plane is legally given the attribute of depth, which in turn shows the difference of lightness and heaviness in architectural psychology.

Reinforced concrete usually conveys a heavy feeling, however, the Sky House, Japan enhances the feeling of floating through the layout of beams beneath the slab. The site is located on a terrain of the city center. The flat box is supported by four $200 \mathrm{~mm} \times 2400 \mathrm{~mm}$ concrete walls in the $6 \mathrm{~m}$ mid-air. Looking up from the southwest corner, the huge height difference even products illusory: The house expresses a kind of desire to free itself from the surrounding walls and fly into the air. 


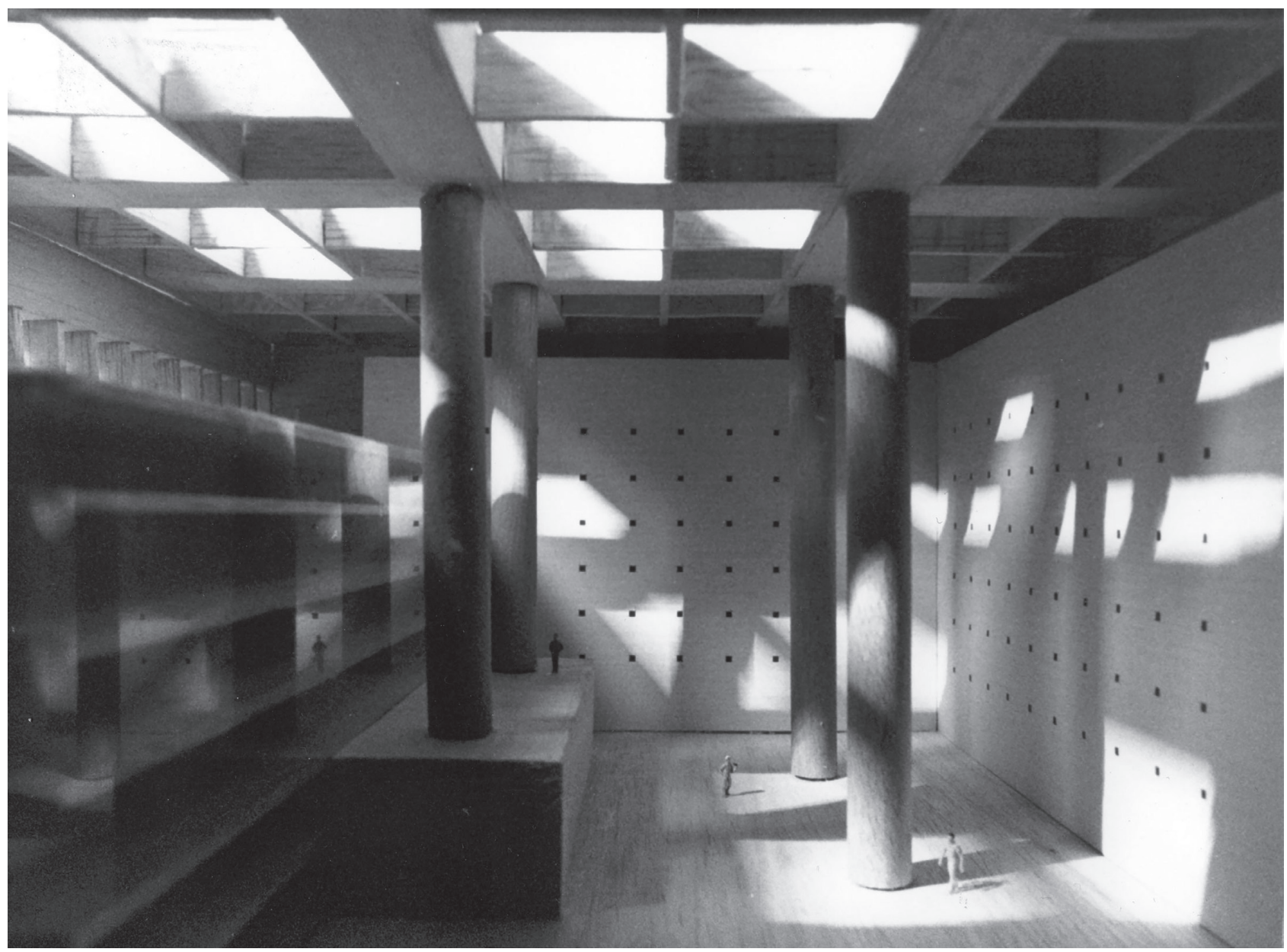

Figure 7. The Model of Caja Granada Savings Bank, Alberto Campo Baeza, 2001. Alberto Campo Baeza Architecture Studio.

"One should be light like a bird, and not like a feather." Italo Calvino quoted French poet Paul Valery's paragraph in his Six Memos for the Next Millennium to explain the essence of lightness. ${ }^{8}$ The lightness of the Sky House, Tokyo, 1958 (fig. 8) is not derived from the lightness of the material, nor is the thinness of the form. On one hand, the opening on four corners makes the supporting of the concrete wall seem effortless; on the other hand, the horizontal operation of various details on the box gives it a visual feeling of lightness. Both of these are related to the beams beneath the slab. The picture below is a comparison of the built house and its early sketch by Kiyonori Kikutake. These two forms are almost the same, but obviously the layout of the beams beneath the slab made an improvement. The sketch shows an equally distributed beams on the waffle slab, while the final built house adopted a hierarchical primary and secondary beam system. Beneath the $7.2 \mathrm{~m}$ square floor, there are actually four levels of beams in supporting and expressing:

The two primary beams are respectively connected to the walls and orthogonal to the center of the slab, which divide the floor into four quadrants like a Cartesian coordinate system. The side beams are supported by four concrete walls and distributed along the four sides, and then form four cantilevered corners. The four beams of the first level are parallel to the side beams, and the depiction of the double lines strengthens the existing level of the floor, and at the same time divides a square lattice in each quadrant; The four beams of the next level are parallel to the side beams, and the depiction of the double lines strengthens the original horizontality of 

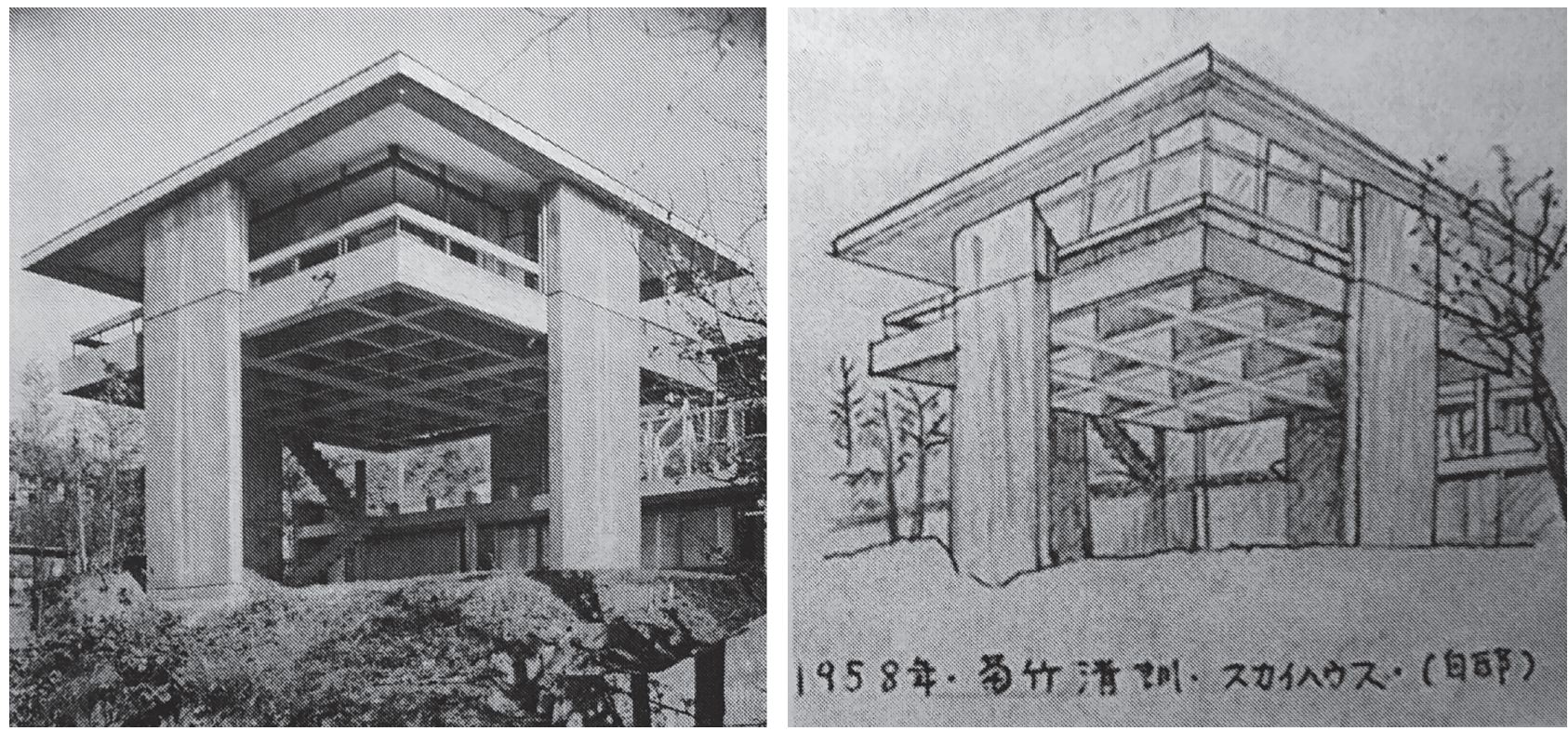

Figure 8. The Comparison of Sky House's Built State and Early Sketch. Kiyonori Kikutake. 1958. Metabolism, the City of the Future: Dreams and Visions of Reconstruction in Postwar and Present-Day Japan, Mori Art Museum.

the floor. At the same time a square lattice in each quadrant forms. The beams of the lowest level divide the square lattice within each quadrant into nine smaller squares. The existence of these nine smaller squares strengthens the independence of each quadrant and exacerbates the disintegration of the slab as a whole piece of homogeneous and heavy plane.

Acting as "trampoline lines," the concrete slabs up to $650 \mathrm{~mm}$ in the mid-air, and completed the spatial expression of "light like a bird."

\section{Spatial Prop - Participating in the Generation of Form}

In the context of Japanese architectural design, the term structure encompasses the meaning of framework + place. The structure is not only a technical concept, but also a place with spatial concept. When the beam exists as a framework + place, its way of intervening in space will let it be a kind of prop of spatial expression.

The form of National Museum of Western Art, Tokyo, 1959 by Le Corbusier is a flat square box. The framework of the museum is made up of $7 \times 7 \mathrm{~m}$ column grid. In the center of the box a two-span two-story lighting atrium exists. A space tetrahedron is formed on the top of the atrium. The tetrahedron is an isosceles triangle bottom surface formed by three points of the atrium and opposite points on the opposite side of the atrium. The bottom of the isosceles triangle extends vertically upward to form a skylight facing the north. Under the tetrahedron, it is a structure with a central column and a $X$ crossing beams standing quietly under the illumination of the sky. This column is located at the very center of the $7 \times 7$ column grid, together with the $\mathrm{X}$ crossing beams, it become the most expressive element in the atrium. The expression of the joint seems quite articulate and forceful. The surface of the structure is board-formed concrete texture. Under the diffuse reflection from the skylight, the rough traces left by the wooden formwork make the form of this structure more well-defined. It is highlighted in the contrast with the skylight and the white wall of the atrium.

\section{Spatial Protagonist - Leading the Order of Spatial Tectonic}

Louis I. Kahn once expressed his attitude towards the relationship between mechanical pipelines and the space: I do not like ducts, I do not like pipes. I hate them really thoroughly, but because I hate them so thoroughly, I feel that they have to be given their place. If I just hated them and took no care, I think that they would invade the building and completely destroy it. ${ }^{10}$

Typically, mechanical pipelines are suspended from the top of the interior space. Conventional layout of beams tends to be a negative factor that hinders the placement of ventilation ducts. On one hand, 

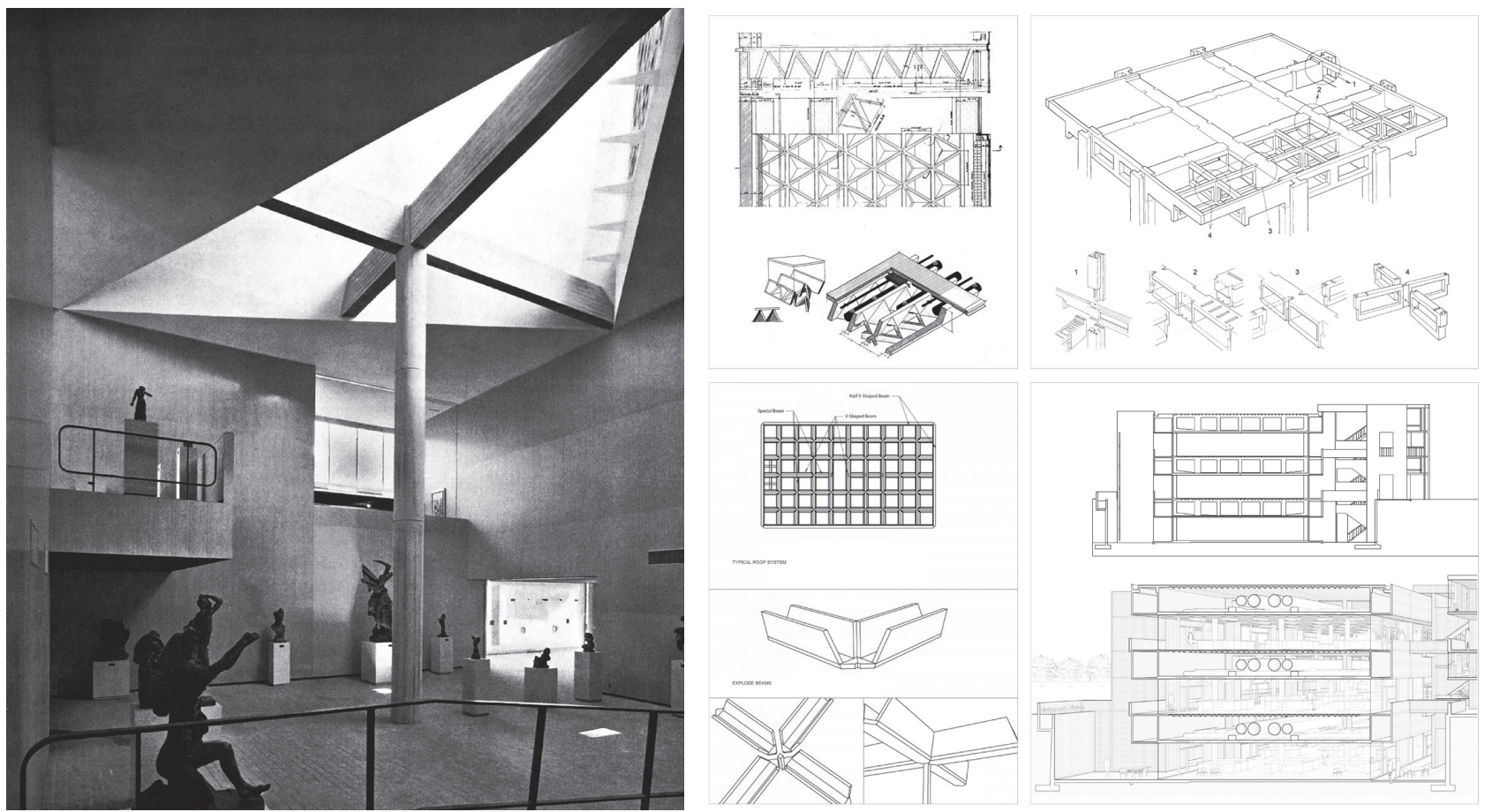

Figure 9. National Museum of Western Art, Tokyo, Le Corbusier, 1959. Anonymous. Takashina Shuji, Le Corbusier \& The National Museum of Western Art (Tokyo: The National Museum of Western Art, Tokyo, 2009).

Figure 10. The development of Louis I. Kahn's beam system integrated with mechanical services. Author self-regroup. 2019. Heinz Ronner, Sharad Jhaveri, Alessandro Vasella, Louis I. Kahn: Complete Work 1935-1974, (Boulder, Colo: Westview Press, 1977), 117. Romaldo Giurgola, Jaimini Mehta, Louis I. Kahn, (Barcelona: Gustavo Gili, 1976), 190. City Tech's OpenLab, The Journal of Architecture. Paul Lewis, Marc Tsurumaki, David J. Lewis, Manual of Section, (New York: Princeton Architectural Press, 2016$), 56$.

the passive placement of the pipeline below the bottom of beams make the room lose height; on the other hand, since exposed pipelines are usually not aesthetically pleasing and if covered by suspended ceiling, the inherent quality of the materials and the spatial consistency of the room would lose. Louis I. Kahn utilize hollow beams as Servant Space to respond to this issue.

The structural frame of the Richard Medical Research Center, Philadelphia, 1965, are constructed by concrete prefabricated components. In each standard floor, the primary beams in two directions are criss-crossed into a kind of waffle-slab, and the prefabricated secondary beams are connected with special construction. The $400 \mathrm{~mm}$ high cavity keeps the mechanical pipelines unobstructed. The lattice formed by the criss-crossed primary and secondary beams enriches the original top surface, and the section of side beams shrink at the ends to make the corners of the building light and transparent.
A similar hollow beam system was applied at the Yale University Art Museum and the Yale University British Art Center. The hollow beams mentioned above only provide access to the mechanical pipelines, however, in Salk Institute, California, 1959, Kahn not only made use of the interstitial characteristics of the concrete Vierendeel trusses, but also even added several interstitial floors. The concrete frameworks with a height of $2.7 \mathrm{~m}$ became the monopoly of the mechanical.

\section{Conclusions}

Since beams are playing an increasingly more important role in architecture, three progressive levels of modern and contemporary architecture practices could be characterized: spatial scenery - as the fifth elevation, spatial prop - participating in the generation of form, spatial protagonist - leading the order of spatial tectonic. Confined to the length of the thesis, a large number of those cases that have been classified could not be mentioned. This classification is based on two main lines: one is the typology classification based 
on plane composition. For example, spatial scenery -as the fifth elevation is subdivided into five sub-categories: Parallel, Lattice, Dogleg-curve, Radial, and Intersection; the other line is about the studies on the methods of combining structural engineering technologies with spatial concepts, which corresponds more to the last two parts of this essay. However, there are not as many cases in the last two parts as in the first one, and a pyramid-like quantitative distribution presents. After all, being able to get the beam involved in the spatial composition requires sufficient depth of thinking and technical ability, and sometimes it needs close cooperation between architects and structural engineers. Despite these difficulties, the basic architectural problem of giving the right form to reinforced concrete structural members deserves further exploration. Analogizing Louis I. Kahn's dialogue with brick, when we ask what a beam want to be, the beam might respond to the desire to be the space itself.

Yang Liu finished his Master in Architecture and Landscape Architecture from Peking University in 2014. As the architectural leader of PKU-UIUC team, he once took part in Solar Decathlon competition. After three years of professional practice in China, since 2017 he has been pursuing his PhD at RWTH Aachen University with the funding from China Scholarship Council. His research focus on the relationship between architecture and structural engineering, especially the cooperation between architect and engineer in early design phase, spatial expression of structural elements, as well as the history of reinforced concrete skeleton buildings in 1950s-1970s.

\section{Notes}

1 "The pediments of the Greek temples are the clearest example of the building limitations imposed by marble. The space between columns is determined by the spanning capability of the monolithic architraves. One might well ask oneself if the lesser span between the end columns, which adds so much to the aesthetic expression of the colonnade, was not the result of the constructional expediency of leaving the length of the end architraves equal to the others instead of increasing them by half a column with." Pier Luigi Nervi, Aesthetics and Technology in Building, trans. Robert Einaudi (Cambridge: Harvard University Press 1965), 11.

2 Lie Zi, Lie Zi: Von der Kunst, auf dem Wind zu reiten, trans. Wolfgang Kubin (Freiburg: Verlag Herder, 2017), 32.

3 Ye Fan, Book of the Later Han, (Beijing: Zhonghua Press, 2000), Volume 62.

4 Kenneth Frampton, Studies in Tectonic Culture: The Poetics of Construction in Nineteenth and Twentieth Century Architecture (Cambridge: MIT Press Ltd., 1995), 127.

5 "Reinforced concrete structures are skeletons by nature. No gingerbread. No fortress. Columns and girders eliminate bearing walls. This is skin and bone construction." Mies van der Rohe, "Bürohaus," G, no. 1 (July 1923): 3.

6 Ibid.

7 Alberto Campo Baeza, Alberto Campo Baeza: Idea, Light and Gravity (Japan: Toto, 2009).

8 Italo Calvino, Six Memos for the Next Millennium, trans. Geoffrey Brock (London: Penguin Books, 2016), 11.

9 "A beam is a sudden contraction in a force field... Beams are trampoline lines and slabs act as reservoirs for hidden patterns in the flow of load." Cecil Balmond, Informal (Munich: Prestel, 2002), 121.
${ }^{10}$ Reyner Banham, The Architecture of the Well-tempered Environment (London: The Architecture Press, 1969), 249. Kahn's statement was first published in World Architecture (London: Studio Books, 1964).

\section{Bibliographic references}

- Balmond, Cecil. Informal. Munich: Prestel, 2002.

- Banham, Reyner. The Architecture of the Well-tempered Environment. London: The Architecture Press, 1969

- Calvino, Italo. Six Memos for the Next Millennium. Translated by Geoffrey Brock. London: Penguin Books, 2016.

- Campo Baeza, Alberto. Alberto Campo Baeza: Idea, Light and Gravity. Japan: Toto, 2009.

- Fan, Ye. Book of the Later Han. Beijing: Zhonghua Press, 2000.

- Frampton, Kenneth. Studies in Tectonic Culture: The Poetics of Construction in Nineteenth and Twentieth Century Architecture. Cambridge: MIT Press Ltd., 1995.

- Nervi, Pier Luigi. Aesthetics and Technology in Building. Translated by Robert Einaudi. Cambridge: Harvard University Press, 1965.

- Van der Rohe, Mies. "Bürohaus." G, no. 1 (July 1923): 3.

- Zi ,Lie. Lie Zi: Von der Kunst, auf dem Wind zu reiten. Translated by Wolfgang Kubin. Freiburg: Verlag Herder, 2017. 